\title{
CD2 Expressing Cell Measurement
}

National Cancer Institute

\section{Source}

National Cancer Institute. CD2 Expressing Cell Measurement. NCI Thesaurus. Code C103366.

A count of the CD2 expressing cells per unit of a biological specimen. 